(Aus der biologischen Versuchsanstalt in Wien.)

\title{
Änderung des Phototropismus bei Küchenschaben durch Erlernung.
}

\author{
Vorläufige Mitteilung. ${ }^{\mathbf{1}}$ ) \\ Von
}

Dr. J. S. Szymanski.

(Mit 1 Textfigur.)

Die Experimente mit Küchenschaben (Periplaneta orientalis L.), über welche ich hier in aller Kürze berichten will, bezwecken festzustellen, in welchem Maasse das angeborene Verhalten dieser Tiere sich durch Erlernung ändern lässt.

Küchenschaben vermeiden Licht und suchen das Dunkel auf, wie dies schon $\mathrm{Graber^{2 }}$ ) nachgewiesen hat. Die Tiere wurden mit Hilfe der "punish method" ${ }^{3}$ ) dahin gebracht, dieses Benehmen zu ändern, und zwar sich von nun an im Lichte aufzuhalten und das Dunkel zu vermeiden.

Der Apparat, welchen ich für meine Versuche benutzte, ist in der beifolgenden Figur ahgebildet.

Der Boden des Apparates bestand aus 29 isolierten Kupferplatten; jede Platte war $0,5 \mathrm{~cm}$ breit; die Entfernung zwischen zwei nebeneinander liegenden Platten betrug $0,1 \mathrm{~cm}$. Alle geradzahligen Platten waren mit einer langen Platte verbunden, welche an einer Seite des Bodens befestigt wurde; alle ungeradzahligen Platten hingen mit der gleichen Platte auf anderer Seite des Bodens zusammen. Beide seitlichen Platten waren mit einem Induktions-

1) Die genaue Beschreibung dieses Versuches erscheint in Journal of Animal Behavior.

2) Graber, Grundlinien zur Erforschung des Helligkeits- und Farbensinnes der Tiere S. 147-157. 1884.

8) Yerkes, The dancing mouse S. 98-99. 1907. 
apparat verbunden, der durch einen Akkumulator von zwei Volt betrieben wurde. Auf solche Weise konnten beim Durchfliessen des Stromes die paarigen Platten als eine, die unpaarigen als zweite Elektrode fungieren. Über den stromleitenden Teil des Apparates wurde ein gläsernes Kästchen ohne Boden von $19 \mathrm{~cm}$ Länge, $2,7 \mathrm{~cm}$ Breite und $8,5 \mathrm{~cm}$ Höhe gestellt (s. Fig. $a c$ ); das Kästchen war zu zwei Fünftel mit schwarzem Papier bedeckt (s. Fig. $d b$ ).

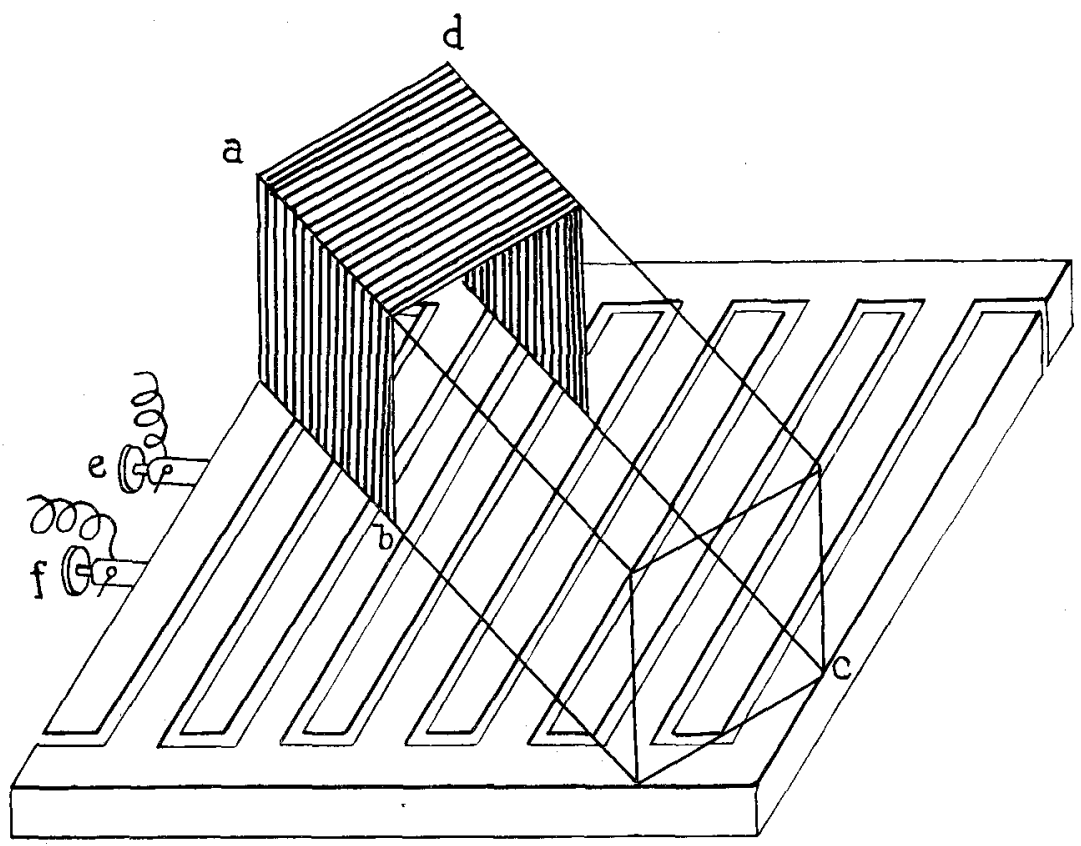

Fig. 1. $a c$ Glaskästchen, $b d$ mit schwarzem Papier bedeckter Teil des Kästchens, $e$ und $f$ Elektroden.

Die Vorversuche, welche ich mit demselben Apparate ausführte, indem ich das oben beschriebene Kästchen durch ein anderes ohne schwarzes Papier ersetzt hatte, haben gezeigt, dass die wirksamste Reaktion der Schaben bei einem Rollenabstand von $12-13 \mathrm{~cm}$ eintrat.

Sämtliche Tiere, mit welchen ich erperimentierte, waren männliche, ca. 1,5 Jahre alte Larven. Die definitiven Versuche wurden in solcher Weise angestellt, dass ich ein Tier in den beleuchteten Teil des Kästchens (s. Fig. $b c$ ) setzte. Die Schabe lief unmittelbar darauf in der Richtung des dunklen Teiles des Kästchens hin; sobald das Tier den dunklen Teil betrat, liess ich den Strom auf dasselbe 
134 J. S. Szymanski: Änderung des Phototropismus bei Küchenschaben etc.

einwirken. Die Schabe lief vorwärts ins Dunkle und dann, nachdem das Tier die Wand erreicht hatte, kehrte es um und erschien wieder im beleuchteten Teile. In demselben Moment schaltete ich den Strom aus. Nach Verlaufe von kurzer Zeit lief das Tier wieder ins Dunkle und bekam wieder den Strom zu verspüren. Im Momente als das Tier in den beleuchteten Teil zurückgekehrt war, schaltete ich wieder den Strom aus usf. Nachdem ein Tier mehr oder weniger Schläge (je nach den individuellen Differenzen) bekommen hatte, trat schliesslich ein Moment ein, in welchem die Schabe, indem dieselbe im beleuchteten Teile in der Richtung gegen das Dunkle lief und die Grenzlinie zwischen den beleuchteten und den dunklen Teilen erreichte, plötzlich stehen blieb und nach kurzer Verzögerung, anstatt. ins Dunkle weiter zu laufen, wieder in den beleuchteten Teil zurückkehrte.

Den Versuch habe ich als gelungen betrachtet, wenn die Schabe, welche im beleuchteten Teile in der Richtung gegen das Dunkle hin rannte, zehnmal nacheinander, ohne einen Schlag zu bekommen, wieder in den beleuchteten Teil zurückkehrte, wenn sie die Grenzlinie zwischen dem beleuchteten und dem dunklen Teile erreicht hatte. Alle zehn auf diese Weise geprüften Schaben zeigten sich fähig dies zu leisten. Der Unterschied zwischen den einzelnen Tieren bestand in der Anzahl der Schläge, welche ein Tier bekommen musste, um die gewünschte Höhe der Umkehrungen zu erreichen. Während z. B. bei Nr. 4 bloss 16 Schläge hierzu nötig waren, mussten bei Nr. 10118 Schläge angewendet werden, um das definitive Resultat zu bekommen. Alle anderen Fälle schwankten zwischen diesen beiden Extremen.

Ebenso schwankte in weiten Grenzen die Zeit, während welcher die Tiere das erlernte Benehmen beibehielten (zwischen $3^{\prime} 53^{\prime \prime}$ bis $\left.55^{\prime} 0^{\prime \prime}\right)$. Das Erlernte geht aber nicht definitiv verloren, wie dies die Versuche mit Wieder-Erlernen zeigten. Während z. B. Nr. 1 bei dem ersten Versuche zwecks definitiven Erlernens 37 Schläge bekommen musste, führte dasselbe Tier bei abermaliger Prüfung am neunten Tage nach der ersten Prüfung schon nach 7 Schlägen die gewänschten zehn Umkehrungen aus. 